\title{
Automobile Industry under China's Carbon Peaking and Carbon Neutrality Goals: Challenges, Opportunities, and Coping Strategies
}

\author{
Fuquan Zhao, ${ }^{1,2}$ Xinglong Liu $\mathbb{D}^{1},{ }^{1,2}$ Haoyi Zhang, ${ }^{1,2}$ and Zongwei Liu $\mathbb{D}^{1,2}$ \\ ${ }^{1}$ State Key Laboratory of Automobile Safety and Energy, Tsinghua University, Beijing 100084, China \\ ${ }^{2}$ Tsinghua Automobile Strategy Research Institute, Tsinghua University, Beijing 100084, China \\ Correspondence should be addressed to Zongwei Liu; liuzongwei@tsinghua.edu.cn
}

Received 21 September 2021; Revised 28 November 2021; Accepted 20 December 2021; Published 12 January 2022

Academic Editor: Wei Zhang

Copyright (c) 2022 Fuquan Zhao et al. This is an open access article distributed under the Creative Commons Attribution License, which permits unrestricted use, distribution, and reproduction in any medium, provided the original work is properly cited.

China has already committed to peaking carbon dioxide emissions by 2030 and achieving carbon neutrality by 2060 (referred to as the 30.60 Target), which has brought both daunting challenges and great opportunities to the automobile industry in China. However, there is still a lack of comprehensive and in-depth studies on the challenges, paths, and strategies for reducing carbon emissions to fulfill the 30.60 Target in automobile industries. Therefore, this paper proposes low-carbon development strategies for China's automobile industry. This study's method is to integrate the results from different literature to summarize the status, challenges, opportunities, and refine the coping strategies for carbon emission of the automobile industry. The results indicated that the paths for achieving the 30.60 Target include joint carbon emission reduction by upstream and downstream enterprises inside the industry. It also needs cross-industry and cross-sector coordinated decarbonization outside the industry. Meanwhile, the low-carbon policy and regulation system should be established to provide a direct driving force and fundamental guarantee for the low-carbon development of China's automobile industry.

\section{Introduction}

To date, thousands of experts and scholars worldwide have proved that global warming is real with all kinds of scientific evidence [1]. A consensus has been reached that the surge in human-caused carbon emissions is the primary cause of global warming. The concept of carbon neutrality is designed to control global temperature rise [2]. China committed to peaking carbon dioxide emissions $\left(\mathrm{CO}_{2}\right)$ by 2030 and achieving carbon neutrality by 2060 (the 30.60 Target) in September2020 [3]. China emitted about 10.2 billion tons of carbon in 2020. It accounts for about one-third of global carbon emissions, twice that of the United States and three times that of the European Union [4]. Realizing China's carbon neutrality target is crucial for global carbon neutrality.

The transport sector has contributed about $10 \%$ of China's carbon emissions in recent years. Road transport carbon emissions are the primary source of carbon emissions from the transport sector, accounting for about $73 \%$ in 2018, as shown in Figure 1 [5]. The carbon emissions of the automobile industry accounted for about $97.8 \%$ of the road transport sector in 2020 [6]. The automobile industry is one of the significant energy consumption sectors and greenhouse gas emissions. Meanwhile, the automobile industry has a high potential to reduce carbon emissions due to immature technologies, such as battery manufacturing technologies [7]. Thus, the automobile industry is an essential part of China's efforts to achieve the 30.60 Target [8].

Recently, a new round of scientific and technological revolution is driving the overall restructuring of the automobile industry, which is moving faster with the carbon neutrality goal [9]. The Society of Automobile Engineering of China (China-SAE) in the Energy-Saving and New Energy Vehicle Technology Roadmap 2.0 has planned the time point for the automotive industry to achieve its carbon reduction 


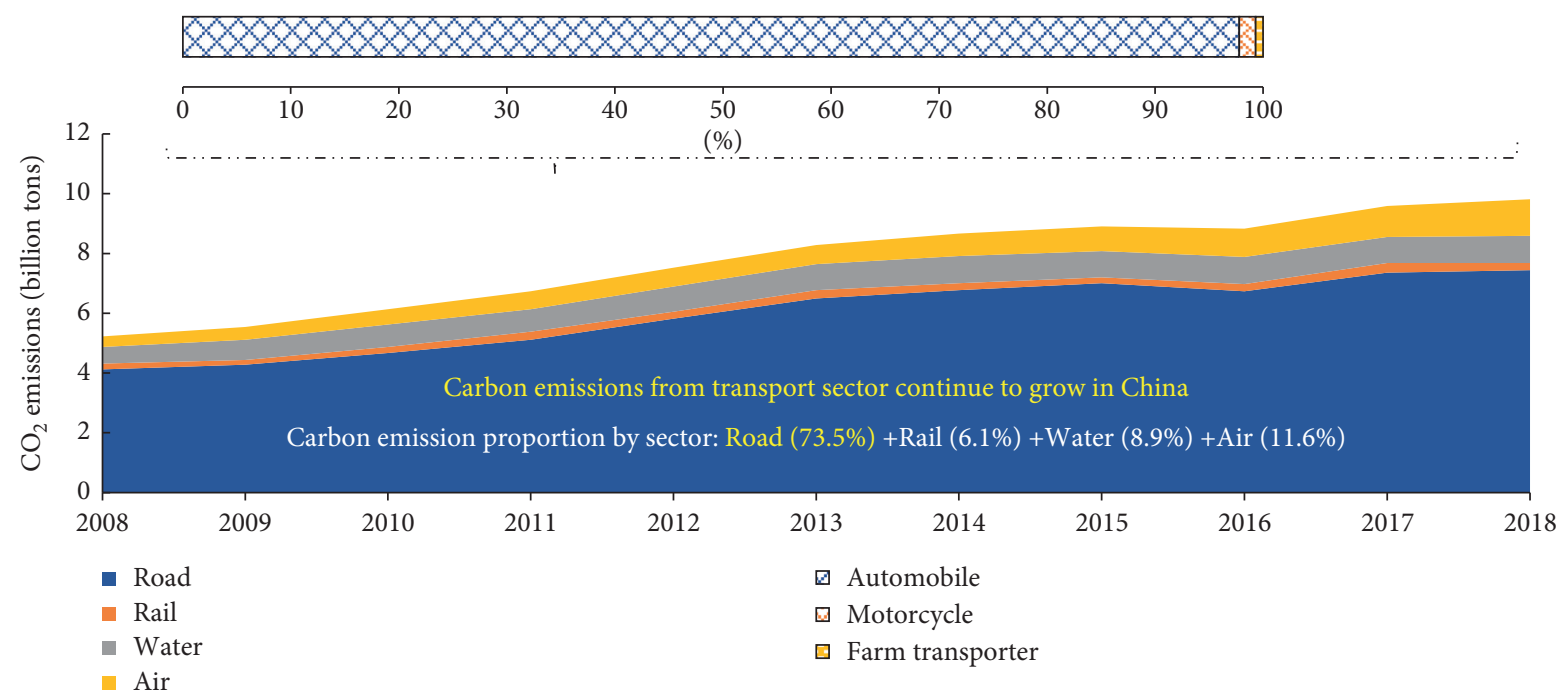

Figure 1: Carbon emission of the road transport sector and automobile industry $[5,6]$ (note: the carbon emissions of the automobile industry account for about $97.8 \%$ of the road transport sector in 2020).

goals. It proposed that the automobile industry should peak carbon emissions by 2028 and achieve carbon neutrality by 2050 to smoothly achieve China's 30.60 Target [10]. It means that the automobile industry in China faces daunting challenges under the 30.60 Target.

There are many studies about the carbon emission of the automobile industry while mainly concentrating on three aspects. First, the literature focused on how to calculate the total carbon emission of the automobile industry. Lee et al. explored an eco-control approach for carbon accounting for supply chain management in the automobile industry. This study finds that eco-control can foster alignment between a firm's carbon management strategy and carbon performance measurement and provides useful quantified information for corporate decision-makers [11]. Hao et al. built a bottom-up model to address energy, environmental impacts of greenhouse gas emission reduction from the passenger vehicle fleet. The results indicate that for passenger vehicles, the target of GHG emissions reduction generally synergizes with petroleum security enhancement, urban air quality improvement, and transport cost reduction but conflicts with the targets of rare metal conservation and transport well-being improvement [12]. Second, the literature paid attention to reducing carbon emission technologies. Qiao et al. conducted a comparative study on life cycle $\mathrm{CO}_{2}$ emission from electric and conventional vehicles in China. The results showed that the $\mathrm{CO}_{2}$ emissions from the production of an electric range from 14.6 to $14.7 \mathrm{t}, 59 \%$ to $60 \%$ higher than the level of an ICEV, 9.2 $t$ [13]. Wu et al. investigated obstacle identification, analysis, and solutions of hydrogen fuel cell vehicles for application in China under the carbon neutrality target. The results revealed that hydrogen fuel cell vehicles application is one of the effective measures of carbon emission reduction, and the economic, technical, social, and political obstacles should be addressed [14]. Third, the literature investigated the impact of carbon policy on the automobile industry. Du et al. conducted a study focused on policymaking and its impact on the automobile industry in the context of carbon neutrality. They concluded that carbon neutrality is a problem that automobile companies must face and should set targets and time nodes related to carbon neutrality as soon as possible and speed up implementing specific measures [15]. Du et al. studied the costs and potentials of reducing $\mathrm{CO}_{2}$ emissions in China's transport sector based on the energy system analysis. The results underlined the carbon peak policy while making alternative fuel vehicles (AFV) more efficient, which increases the overall cost of emissions reduction [16].

However, there is still a lack of comprehensive and indepth studies on the challenges, paths, and strategies for reducing carbon emissions to fulfill the 30.60 Target in automobile industry [17], because of the short time that China has put forward the carbon neutrality goal. Meanwhile, many scholars paid more attention to the basic research on the technologies for reducing carbon emissions from automobiles and calculating carbon emissions throughout the life cycle. [18]. Therefore, it is important to summarize and point out the strategic directions and technology paths toward low-carbon development of the automobile industry from the macro level.

To bridge these gaps, this paper systematically studies the challenges, opportunities, and coping strategies for China's automobile industry to achieve the 30.60 Target. First, the connotation of China's 30.60 Target is interpreted. Second, the current situation, challenges, and opportunities of the automobile industry to reduce carbon emission are analyzed. Finally, the path and direction of the carbon neutrality goal are proposed based on the current situation and development vision of the automobile industry in China.

\section{Interpretation of China's 30.60 Target}

2.1. Connotations of China's 30.60 Target. Carbon neutrality refers to zero carbon dioxide emissions. It can be achieved by offsetting the total greenhouse gas emissions directly or indirectly. The emissions are generated by enterprises, 
organizations, or individuals within a certain period by afforestation, energy conservation, and emission reduction. Carbon peaking refers to the steady decline of carbon emissions after reaching a plateau. The process of achieving the 30.60 Target in China is shown in Figure 2, from which we can see the difference between carbon peaking and carbon neutrality goals.

It should be said that the technical difficulty in achieving the goal of peaking carbon emissions by 2030 is relatively low for China. It can be achieved by mainly adopting carbon reduction technologies (referring to technologies for reducing carbon emissions) and partially adopting zero-carbon technologies (referring to the use of clean energy without carbon emissions) [19]. In comparison, the technical difficulty in achieving the carbon neutrality goal by 2060 is exceptionally high. In addition to applying carbon reduction and zero-carbon technologies, it is also necessary to adopt negative carbon technologies (meaning capturing carbon from the environment and sequestering or reusing it, or absorbing carbon from the natural environment using tree planting, etc.) [20]. In addition, according to China's climate management authority up to date, the carbon peaking goal only refers to the peak of carbon dioxide emissions. In contrast, the carbon neutrality goal refers to the neutrality of all greenhouse gases.

Carbon emissions will gradually enter the plateau period with stable fluctuations around the time of achieving the carbon peaking goal, as shown in Figure 2. The more prolonged carbon emissions stay on the peak plateau after reaching the peak, the shorter the window of time to achieve carbon neutrality and the higher the cost of subsequent decarbonization. Therefore, although carbon peaking must precede carbon neutrality from the timeline perspective, the two must complement specific actions. It makes no sense to peak carbon emissions first and go carbon neutral later. It should be emphasized that carbon peaking is a prerequisite for carbon neutrality - the sooner the carbon peaking goal is achieved, the lower the peak emissions value will be. Thus, the sooner the carbon peaking goal is achieved, the better it is for achieving carbon neutrality. At the same time, the time point of entering the carbon emission plateau should be as early as possible as when the carbon peak occurs. It will promote the industrial application of carbon neutrality technologies and increase the time window for carbon neutrality.

Given the above, carbon peaking and carbon neutrality are intrinsically related and fundamentally different. Generally speaking, carbon peaking is an important milestone and critical time point for carbon neutrality. In contrast, carbon neutrality is the ultimate goal of carbon peaking and the fundamental symbol of a complete transformation of the national development model. Moreover, the carbon peaking goal is not as tricky as carbon neutrality. The carbon neutrality goal limits the time and peak value of the carbon peaking goal. It fundamentally rejects the "cheating" path of raising carbon peak value first and lowering it later. Accordingly, the carbon peaking goal will become more challenging and meaningful under the constraints of the carbon neutrality goal. At the current time point, China must reasonably develop a carbon peaking strategy and factor carbon neutrality in its low-carbon energy transition. Only in this way can we ensure that carbon neutrality could be achieved as scheduled after peaking carbon emissions.

In addition, the 30.60 Target will open a new chapter of human civilization. From an energy perspective, it would accelerate decarbonization on the energy supply side, leading to fossil fuels being replaced entirely, and the proportion of renewable energy will be significantly increased [21]. At the same time, the transformation in energy consumption should also be accelerated. A clean electricitybased energy consumption pattern must be established in the future [22]. From the industry perspective, carbon neutrality will accelerate the adjustment and optimization of industrial structures [23]. Specifically, it can be summarized into three aspects. First, the 30.60 Target will drive the upgrading of relevant technologies and the innovation of industrial models. Second, the 30.60 Target will curb energyintensive industries' expansion and capacities. Third, the 30.60 Target will make the digital economy, high-tech industries, and services the development priorities [24].

From the enterprise perspective, the core competitiveness of enterprises will change. Low-carbon manufacturing and low-carbon products become the necessary ability for enterprises to win competitive advantages [25]. At the same time, the development concept and business model of enterprises will also change. Enterprises must carry out lowcarbon operations throughout the life cycle of the products. They should consider carbon emissions during product use and energy use during the product life cycle, including the production process. Carbon trading management will be the basis for effective business operations in the future. Companies with high-carbon emissions must spend a lot of money buying carbon credits to avoid losing out to the competition. It is expected that in the future, low carbon emissions will become a new economic norm and trade barrier in the world. Companies with high carbon emissions will be shut out of the market [26]. From the perspective of society, there will be fundamental changes in the way people produce and live. The whole society needs to develop a lowcarbon culture. Everyone should have a low-carbon consciousness and start a green and economic low-carbon lifestyle.

\subsection{Challenges Facing China in Achieving the 30.60 Target.} As the world's second-largest economy, China has a daunting task to achieve the 30.60 Target. Figure 3 shows the fossil fuel-related carbon dioxide emissions and the carbon neutralization goal planning of major countries in the world [27, 28]. According to China's carbon emission trend and carbon neutrality plan, its challenges in achieving the 30.60 Target can be summarized as a "tight schedule and heavy task" compared with other countries.

The schedule is tight. China is now the world's largest carbon emitter, while the buffer time from carbon peaking to carbon neutrality is just 30 years. The time gap between carbon peaking and carbon neutrality in most developed countries is $50-60$ years [28]. China's goal of achieving 


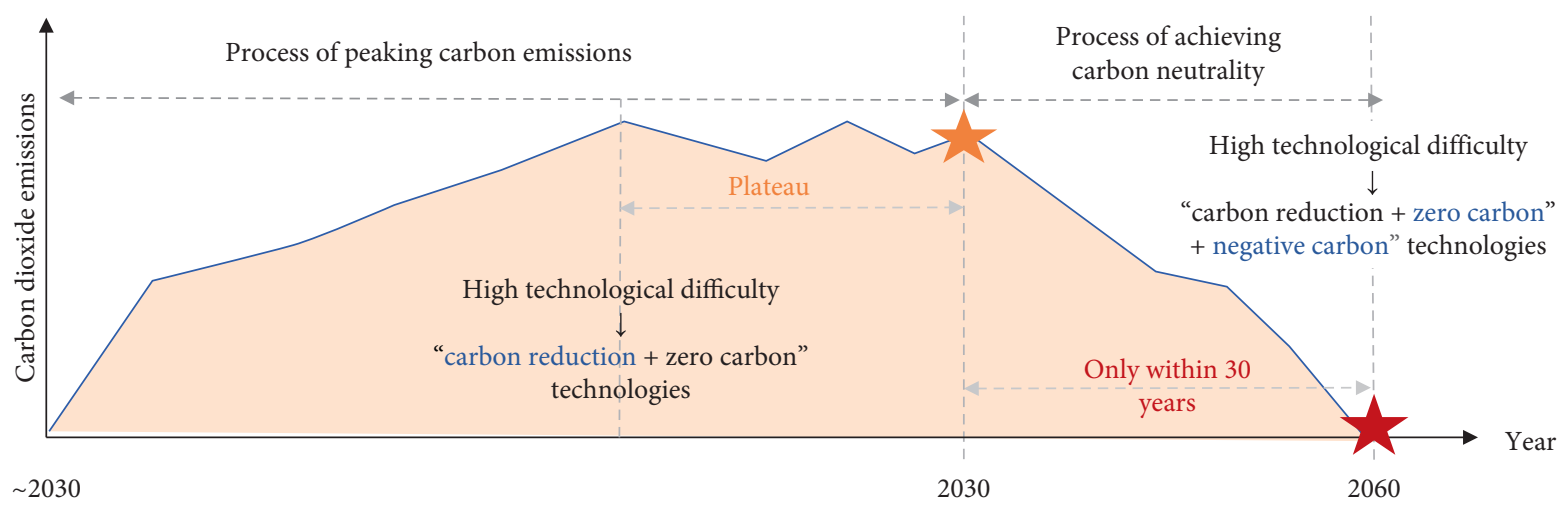

Figure 2: The process of achieving the 30.60 target in China.

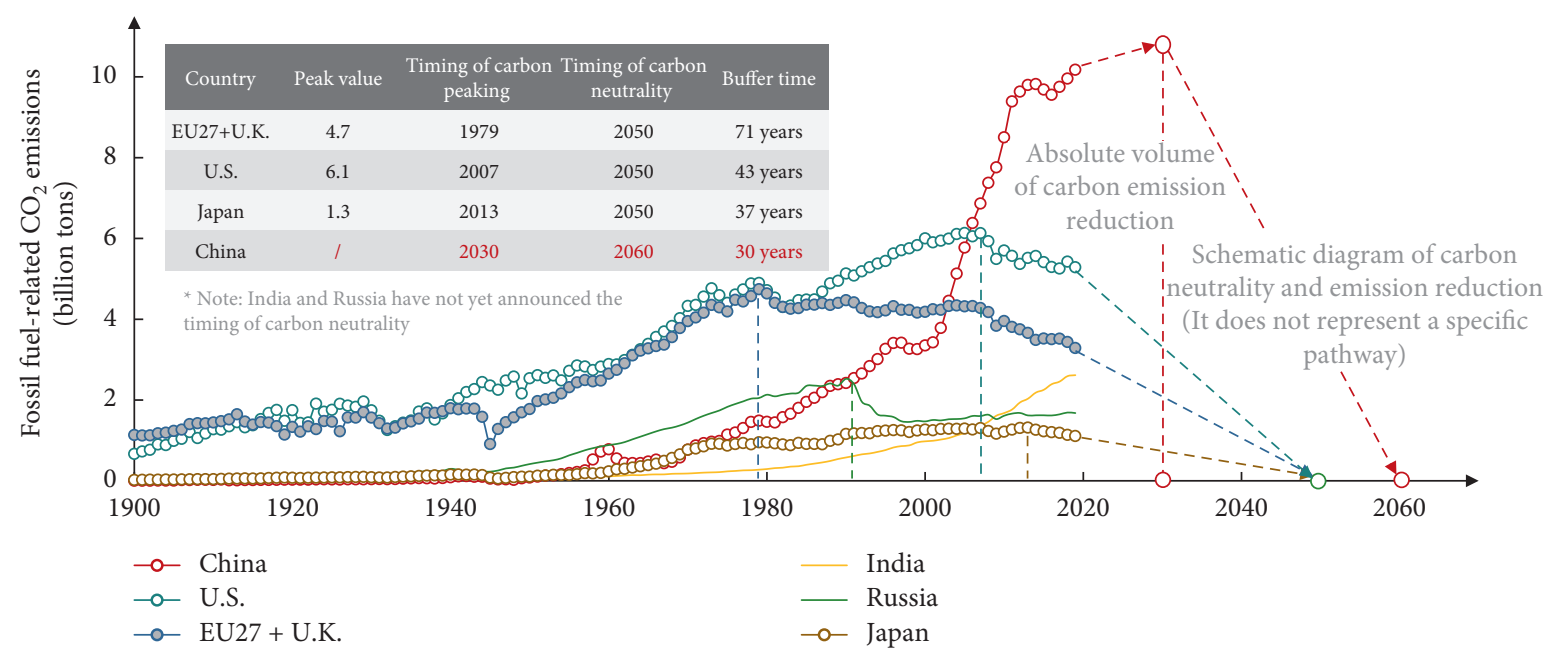

Figure 3: Fossil fuel-related carbon emissions and carbon neutrality plans of major countries in the world [27, 28].

carbon neutrality by 2060 has exceeded the expectations of many international experts. It means that a country like China must control the increase and eliminate the stock of $\mathrm{CO}_{2}$ within 40 years. However, China is developing where its emissions are far from peaking. This challenge is unprecedented for China.

The task is heavy. First, China's carbon emissions have topped the world, as shown in Figure 3. China accounts for about one-third of global carbon emissions, twice that of the United States and three times that of the European Union [4]. At the same time, neither China's industrialization nor urbanization has yet reached its peak. The demand for life services is also in the stage of rapid growth. Many new production capacities and services will be needed to meet the growing needs of the national economy and people's livelihood in the future. If China does not change its development model, carbon emissions will grow further.

Second, the 30.60 Target is an unprecedented and complex national system project involving multiple fields and factors. If any one of them is not fully implemented or linked to the others, it is impossible to achieve carbon neutrality. Therefore, China must think comprehensively and advance as a whole. The government should adopt a topdown approach for strategic deployment and a bottom-up approach for tactical support to implement decarbonization orderly and systematic.

Third, the high-carbon economy itself has development inertia and technological limitations. It is not easy to completely abandon the original development model. At present, China's adoption of low-carbon energy and energy efficiency is relatively low. It is difficult to change the economic growth model in a short time. New products and services require new energy for support, which means China needs to decarbonize both incremental fuels.

Fourth, to achieve the 30.60 Target, economic growth and people's livelihood should be considered. A low-carbon transition at the expense of economic growth is not desirable. China must continue to meet the growing needs of its 1.4 billion people for a better life. It is the prerequisite for implementing carbon peaking and carbon neutrality actions and achieving the 30.60 Target. As a result, China's lowcarbon transition is more challenging than expected.

To sum up, the essence of China's 30.60 Target is the innovation of science and technology, reconstruction of social infrastructure, and transformation of the country's economic development model. These involve the simultaneous transformation of the country's energy mix, industrial structure, industrial foundation, and the accompanying 
transformation of social infrastructure and cultural environment. It is a grand strategy that concerns the fate of the country.

2.3. Overall Strategies to Achieve China's 30.60 Target. Experts and scholars have reached a basic consensus on achieving the carbon neutrality goal for China. A concerted effort must be made from six aspects, such as emission reduction from the source, energy substitution, energysaving, efficiency improvement, recycling, process transformation, and carbon capture [29].

First, we need to pay attention to the following points in the direction and principle of low-carbon development. On the one hand, the universality of the climate problem determines that it is difficult to achieve global temperature control targets through bottom-up emission reduction. Topdown planning is inevitable. On the other hand, the carbon peaking goal and carbon neutrality goal should be considered simultaneously and cannot be separated. It is the basic principle that must be followed [30].

Second, attention needs to be paid to the scope and manner of achieving the carbon neutrality goal. On the one hand, carbon neutrality is reflected in production activities, lifestyle, and values. It is important to emphasize that lifestyle changes are also essential for achieving carbon neutrality. Efforts should be made to encourage society to advocate a green and economic lifestyle. On the other hand, future economic growth should be based as much as possible on carbon-neutral technologies to avoid the costs of subsequent replacement of high-carbon models.

Finally, specific measures to achieve carbon neutrality need to be considered. First, energy supply-side reform needs to be accelerated. The methods include increasing the proportion of renewable energy, building a new energy mix dominated by zero-carbon electricity, and vigorously promoting energy storage technology and industrial layout to ensure a balanced power grid [31]. Second, energy demand-side reform needs to be strengthened. We will comprehensively promote terminal electrification, emission reduction from the source, and energy efficiency improvement in industrial, transportation, and construction sectors [32]. Third, the whole process of industrial production needs to be improved. Targeted measures such as material substitution, technological innovation, process improvement, and equipment transformation should be adopted for the possible carbon emissions in each link [33].

In general, the technologies for achieving the $30 \cdot 60$ Target can be divided into three categories. One is carbon reduction technologies, which are mainly a matter of technological advancement. These technologies include energy efficiency improvements, resource recovery, process innovation, and fuel/feedstock substitution [29]. The second type is zero-carbon technologies, which are mainly about energy substitution. If carbon-based fossil fuels dominate the energy mix, it is impossible to achieve carbon neutrality no matter how many carbon reduction technologies are used [34]. To achieve this goal, China must promote energy decarbonization, including introducing renewable, nuclear, and biomass energy. It should form an energy supply system that contains renewable energy sources and energy storage carriers.

Meanwhile, electric and hydrogen energy should become the primary terminal energy sources. Under this prospect, electric and hydrogen energy will become the leading carriers of human energy in the future. The production, storage, transportation, and use of electric and hydrogen energy will become increasingly critical [35].

The third type is negative carbon technologies, which refer to recycling carbon emissions from human activities. They belong to the scope of carbon sinks, divided into two main types: natural and artificial carbon sinks [36]. Natural carbon sinks include ocean carbon sinks and agroforestry carbon sinks, achieving carbon sequestration through oceans, forests, and so on. This approach is less costly but has limited potential. Artificial carbon sinks refer to carbon capture, storage, and utilization technologies. This approach is costly and requires breakthroughs in the technologies. There is not much application space in the short term, but it is the key technology to achieve carbon neutrality in a long time [37]. Moreover, these technologies will also expand the space for the human use of fossil fuels.

The above explains the strategic thinking, severe challenges, significant opportunities, and overall implementation strategies of China's 30.60 Target. The following will focus on the coping strategies for achieving the 30.60 Target in the automobile industry in China.

\section{Coping Strategies for the Automobile Industry under the 30.60 Target}

Carbon emissions from the transport sector are an integral part of the total carbon emissions of the world and every country. Figure 4 shows the predicted carbon emissions reduction of all sectors of China's transport sector to achieve carbon neutrality $[4,38]$. As we can see from the figure, although the total amount of carbon emissions in China is higher than that in the United States, the carbon emissions from the transport sector in China are still lower than that of the United States. The transport sector contributed $11 \%$ of China's carbon emissions in 2020, well below $37 \%$ in the United States and 24\% globally. It shows that the transport sector in China is still not saturated. There is still a lot of space for development in the future. It also means enormous pressure and potential room for carbon reduction in the transport sector in China.

To achieve carbon neutrality by 2060 , China's transport sector will need to reduce carbon emissions by 75 to 80 percent from the 2015 level, according to the research by Energy Foundation in China on China's mid-and long-term plan for low-carbon development and transformation of its transport sector [38]. Broken down by sector, road transport needs to cut emissions by 81.2 percent, civil aviation by 3.3 percent, and waterways by 5.6 percent to meet the goal. Therefore, the emission reduction of the transport sector should prioritize road transport. In this sense, as an essential part of road transport, the automobile industry will be the key to achieving the carbon neutrality goal in China's transport sector [6]. 


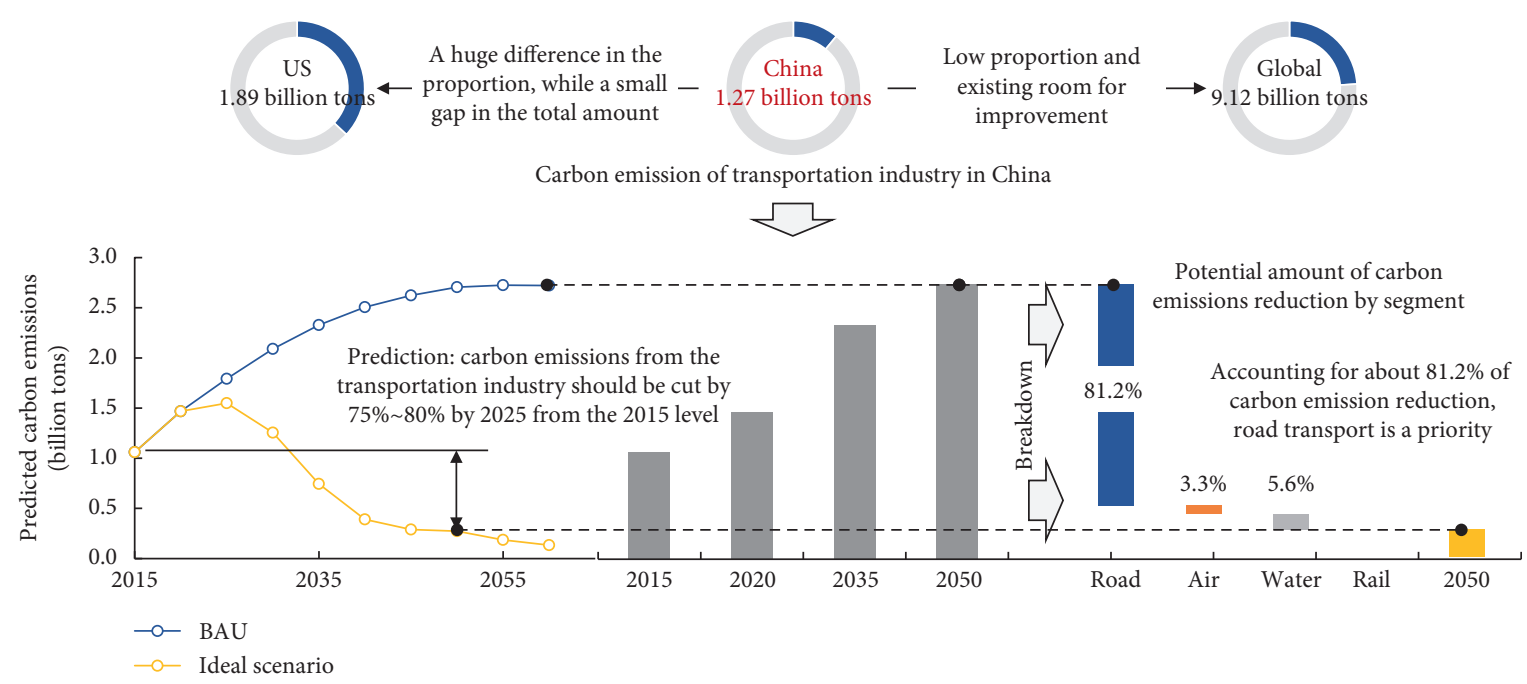

Figure 4: The role of the road transport (automobile industry) sector in achieving the $30 \cdot 60$ target in China $[4,38]$.

In addition, the automobile industry, as a comprehensive manufacturing industry, has a long industrial chain, involves a wide range of fields, and consumes a lot of energy. The automobile industry is a pillar and a carrier in the national economy. Its low-carbon and the zero-carbon transition are also more representative and vital for China.

3.1. Challenges to the Automobile Industry under the $30 \cdot 60$ Target. Compared with other industries, the automobile industry faces three significant challenges in achieving the 30.60 Target.

First, the automobile industry is large and attracts great attention in China. Car ownership per thousand in China is not yet saturated, and carbon emissions from its automobile industry will continue to grow for the foreseeable future. There are 292 million cars in China (as of the second quarter of 2021). China will have nearly 550 million cars by 2050, predicted by Hao et al. [39]. It implies a complex incremental substitution and de-stocking in China's automobile industry. The effect of low-carbon and zero-carbon transformation in the automobile industry will symbolize China's compliance with the international commitment of achieving the 30.60 Target. It is because that the automobile industry is highly concerned and dominant. For example, China is the world's largest market for new energy vehicles, and it is still growing at a high speed. Moreover, the market penetration rate of new energy vehicles has reached 15\% in July 2021, which has attracted global attention [40].

Second, the global economic and trade mechanism has changed, and has increasingly fierce low-carbon competition. The current international political and economic environment is increasingly uncertain. Countries are likely to develop stricter trade policies around carbon emissions, creating new trade barriers. Regulations such as carbon border regulation mechanisms, carbon footprints, carbon leakage laws, etc., will limit the manufacturing model with high carbon emissions and be used for low-carbon emissions. It will affect a country's automobile industry [41]. Taking carbon leakage laws as an example, the European Union is currently discussing legislation to examine the carbon emissions of products from the whole life cycle perspective, which is expected to be implemented in 2023.

With the introduction of carbon leakage laws, those products produced in high-carbon regions will not be allowed to be sold in the relevant legislative areas, or high carbon taxes will be required to be paid. Even if low- or zero-carbon technologies are used in the production process, more attention needs to be paid to electric vehicles with relatively high carbon emissions in the production process [42]. It suggests that automobile enterprises should carry out low-carbon manufacturing and develop low-carbon products in shifting to a low-carbon market. Otherwise, they will not win the competition in the future [43].

Third, the automobile industry alone cannot solve the problems concerning the 30.60 Target. Due to its high interconnection with other industries, the automobile industry cannot achieve carbon neutrality on its own. For example, $90 \%$ of the carbon emissions in the production stage of the automobile come from indirect emissions of high-carbon electricity [44]. Only the adoption of clean energy can accelerate the process of carbon neutrality in the automobile industry. Therefore, the sustainable competitiveness of the automobile industry can only be guaranteed by the coordinated cross-industry development in China.

In short, the automobile industry is likely to be forced to accelerate the pace of achieving the 30.60 Target because of its high carbon emissions and high profile [10]. In this regard, the Chinese government and the automobile industry must have sufficient understanding and expectations.

\subsection{Identification of Key Factors Affecting Carbon Emissions in the Automobile Industry. Carbon emissions of automobiles mainly cover the automobile manufacturing, use, and recycling stages [13]. By analyzing the life-cycle carbon emissions of automobiles, this paper summarizes the key factors affecting carbon emissions in the automobile in- dustry, as shown in Figure 5.}


The factors affecting carbon emissions in the automobile use stage include vehicle carbon emission intensity, structure and level of car ownership, vehicle miles traveled, and carbon emission factors of fuels [45]. Therefore, the following ways can be adopted to reduce the carbon emission intensity in the automobile use stage. First, it can reduce vehicle carbon emission intensity by improving engine thermal efficiency and using hybrid technologies [46] and alternative fuels [47]. These tasks can be completed by automobile companies alone. On the other hand, improving traffic efficiency and reducing congestion can improve the fuel economy of the automotive. Improvements in these jobs will depend on the transport sector. Second, it can optimize the structure and level of car ownership [48]. Examples include reducing the sales of high-carbon cars and increasing lowcarbon cars. Measures should be taken to curb the purchase of and accelerate the elimination of high-carbon cars. Realizing these needs requires a change in people's low-carbon lifestyles [49]. Third, it can reduce vehicle miles traveled. For example, private car trips should be minimized, and people should be encouraged to use buses and subways more often [50]. Besides, we should reduce the use of road transport and increase rail or waterway transport [51]. Meanwhile, optimizing urban planning, increasing the frequency of shared trips, and reducing the number of unnecessary trips are also ways to reduce the vehicle miles traveled [52]. Fourth, it can lower the carbon emission factors of fuels. For example, it should conduct low carbon fuel production to lower the carbon emission factors of fuels.

The factors affecting carbon emissions in the automobile manufacturing stage include energy consumption and material consumption per unit of automobile product manufactured [13]. Therefore, on the one hand, carbon emissions in the automobile manufacturing stage can be reduced by cutting the energy consumption per unit of product manufactured. For example, it can be achieved by reducing fossil fuel consumption, increasing production efficiency, and reducing high-carbon manufacturing processes. On the other hand, it can reduce the material consumption per unit of product manufactured, such as lowering the consumption of high-carbon raw materials [53].

The factors affecting carbon emissions in the automobile recycling stage mainly include the reduction of carbon emissions from vehicle recycling and material recycling [54]. Generally speaking, recycling will significantly reduce carbon emissions from automobile manufacturing. Thus, some scholars have classified carbon emissions in the automobile recycling stage and the material consumption in the automobile manufacturing stage. The control of carbon emissions in the automobile manufacturing and recycling stages mainly depends on the automobile industry. Still, it can only be effectively implemented under the premise of cost control [55].
3.3. Coping Strategies for the Automobile Industry to Achieve Carbon Peaking and Carbon Neutrality Goals. From the above analysis, it can be seen that the automobile industry should not fight alone in the long journey toward carbon peaking and carbon neutrality goals. In contrast, it should coordinate effectively with other related industries and fields. Decarbonization is a systematic change for the automobile industry.

Inside the automobile industry, carbon emission reduction must be achieved through the linkage between the upstream and downstream of the industrial chain, including design, procurement, production, use, recycling, service, and other links. And decarbonization must be achieved across the industrial automobile chain and throughout the life cycle [56]. Outside the automobile industry, decarbonization of the automobile industry must be achieved through crossindustry and cross-sector collaboration [57]. The energy industry needs to provide zero-carbon energy for the automobile industry. The transport sector should provide low/ zero-carbon mobility application scenarios in the automobile industry. It requires establishing a low-carbon policy and regulation system with carbon trading as the core, which will provide the most direct driving force and fundamental guarantee for the low-carbon and decarbonization transformation of the automobile industry. The coping strategies for the automobile industry to achieve the carbon peaking and carbon neutrality goals are as shown in Figure 6.

Therefore, the coping strategies for the automobile industry to achieve carbon peaking and carbon neutrality goals can be summarized as follows. The carbon emission reduction in the automobile industry needs to be centered on the carbon emission reduction throughout the life cycle; it should be based on the coordinated decarbonization of multiple industries and sectors and finally supplemented by negative carbon technologies.

\subsubsection{Inside the Automobile Industry: Carbon Emission} Reduction throughout the Life Cycle. To achieve carbon emission reduction throughout the life cycle, the automobile industry should take the following measures. The first is to reduce carbon emissions in the production process, including energy efficiency improvement, process innovation, fuel/raw material substitution, and green energy use. According to the China Automobile Technology and Research Center calculations, the amount of carbon emissions in the automobile production stage in China is maintained between 0.06 and 0.07 billion tons per year [44]. The second is to change the use of carbon products, including energy conservation and efficiency improvement and operational efficiency improvement [58]. In particular, low-carbon/zerocarbon products should be used more intensively to dilute their production's energy and emissions' costs [59]. At the same time, the product's service life should be extended as much as possible. In the past, this was mainly to reduce costs while reducing production to reduce carbon emissions in the 


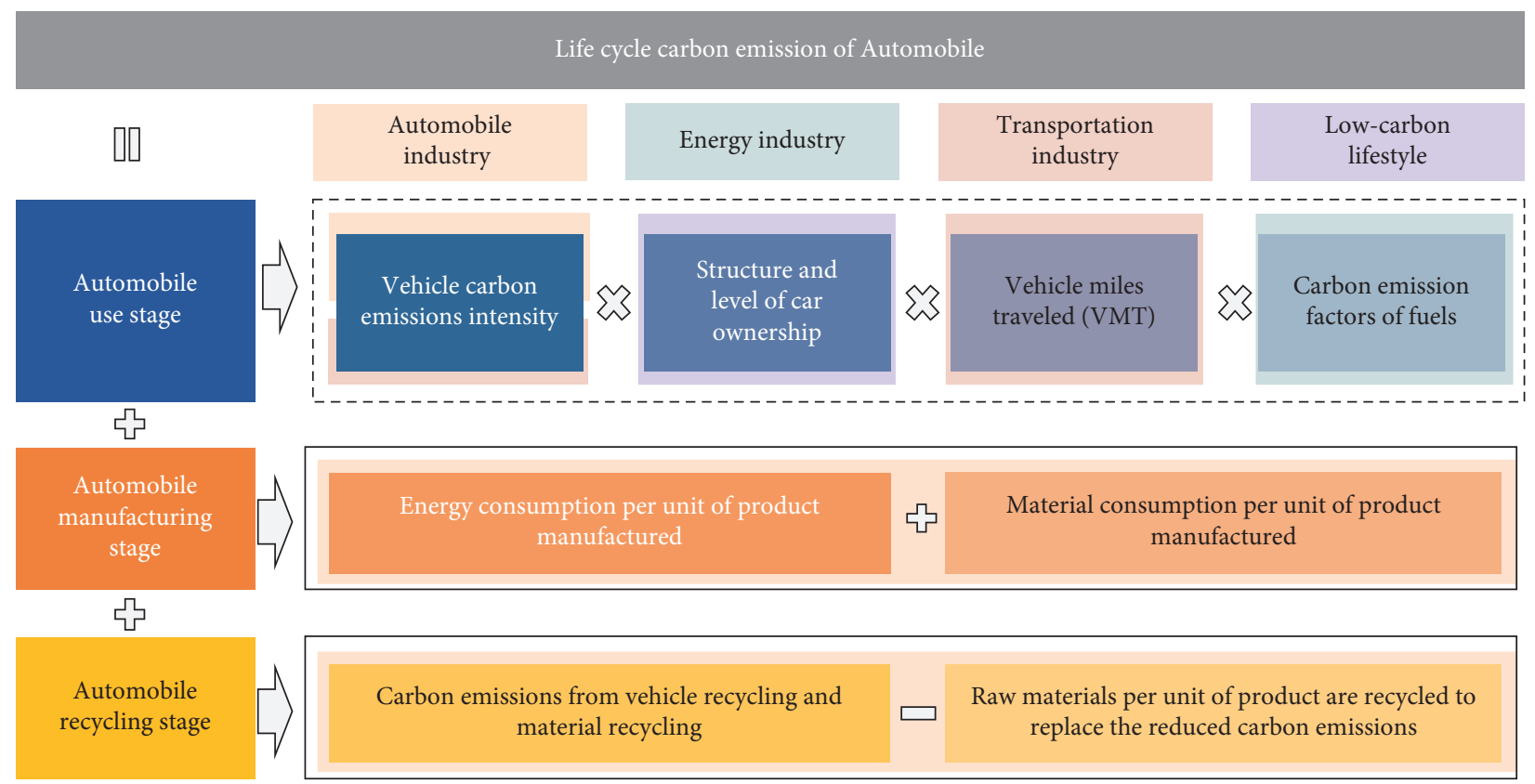

FIGURE 5: Identification of key factors affecting carbon emissions in the automobile industry.

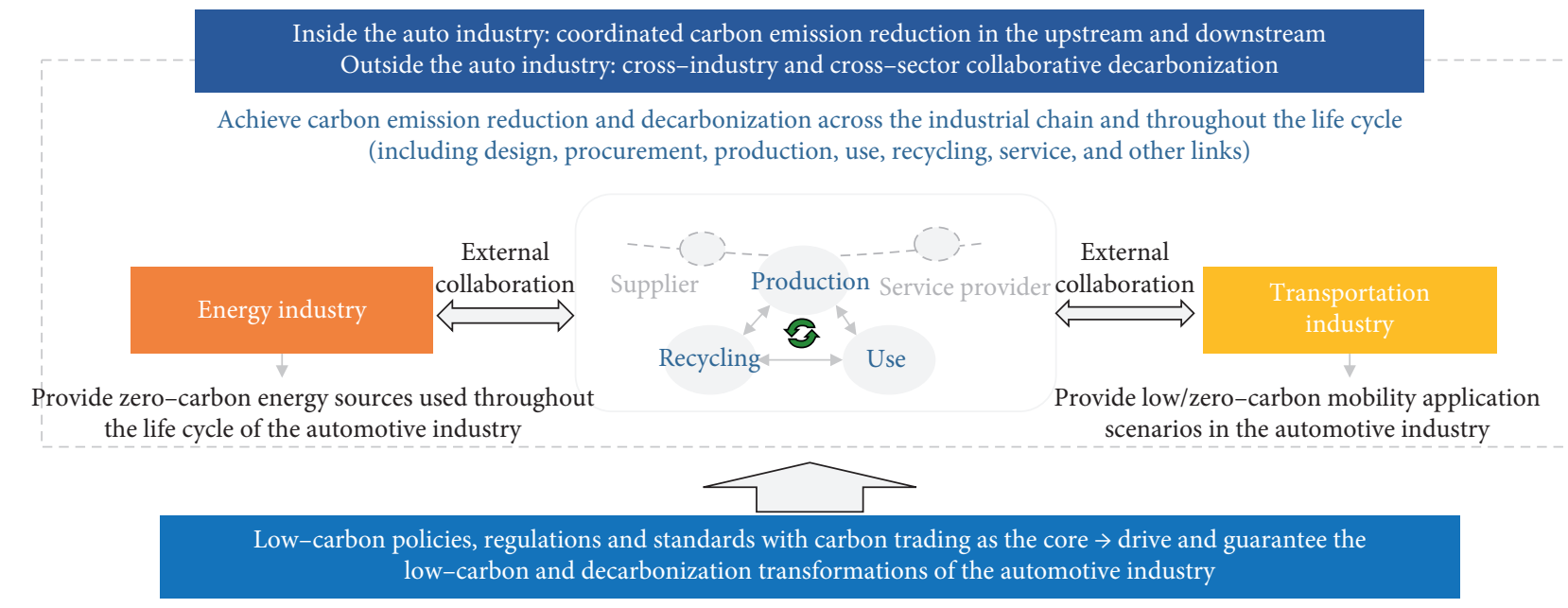

Figure 6: Coping strategies for the automobile industry to achieve carbon peaking and neutrality goals.

future [60]. In addition, in the structure of car ownership in China's automobile industry, commercial vehicles and passenger cars account for $16.7 \%$ and $83.3 \%$, respectively. However, the corresponding carbon emissions account for $56 \%$ and $44 \%$, respectively. Therefore, commercial vehicles will be an essential field of carbon emission reduction in the transport sector in the future [61]. Low-carbon technologies for commercial vehicles should be promoted in the future. For example, promoting the adoption of fuel cells in commercial vehicles is a good move.

The third is to reduce carbon emissions through recycling, including improving the efficiency of material recycling and developing a circular economy. Material recycling means that the production of raw materials can be reduced. It will effectively reduce the carbon emissions of raw material production from mining, processing to application. The carbon emissions from electric vehicles can be cut by $8 \%-$ $11 \%$ through recycling (from Grave to Cradle stage) [62]. In particular, the recycling of power batteries will significantly reduce the overall carbon emissions of electric vehicles [63]. Fourth, the carbon emission reduction target of the automobile industry can be achieved by reducing the carbon emissions of the supply chain. Specific methods include material substitution and process innovation. The former solves the carbon emission problem of the upstream industrial chain from the source of materials while the latter effectively reduce carbon emissions in the production process of components [64]. For example, many automobile enterprises have carried out low-carbon supply chain management through collaboration with suppliers [11]. 
3.3.2. Outside the Automobile Industry: Cross-Industry and Cross-Sector Collaborative Decarbonization. In terms of external cooperation, efforts are mainly reflected in the cross-industry and cross-sector coordinated decarbonization. First, carbon emission reduction in the automobile industry can be realized by optimizing the structure of the energy industry. For example, the share of clean energy can be steadily increased [65]. At the same time, the development of electric vehicles and hydrogen fuel cell vehicles should be taken into account in the future to increase the consumption of renewable energy. In addition, efforts should be made to break through the challenges facing vehicle-to-grid (V2G) technology and business models to promote the development of a smart grid [66]. Second, the structural optimization and redistribution of the transport sector can reduce the carbon emissions of the automobile industry. For example, we can continuously enrich the application scenarios of low-carbon/zero-carbon automobile products and improve their usage intensity and operational efficiency. In the future, the barriers between smart cars, smart transportation, and smart cities can be broken down to realize the large-scale low-carbon application of smart electric vehicles. Finally, carbon emissions can be eliminated through negative carbon technologies. Some hard-to-eliminate carbon emissions in the automobile industry can be neutralized through reforestation and the application of carbon capture, storage, and utilization technologies.

3.3.3. Establishment of a Low-Carbon Policy, Regulation, and Standard System with Carbon Trading Policy as the Core. The policy, regulation, and standard system are essential drivers for the transformation of automobile power and the development of the automobile industry [67]. The carbon peaking and carbon neutrality goals have put forward new requirements for the integrity of the automobile industry's policies, regulations, and standards. It is necessary to further improve the policies, regulations, and standards for the automobile industry.

First of all, automobile test and evaluation standards are the foundation of the automobile industry's policy, regulation, and standard system. Specifically, passenger vehicle fuel economy test standards for passenger cars provide a benchmark for the quantitative evaluation of vehicles' energy consumption. Meanwhile, they also serve as the basis for the implementation of incentive policies, such as the corporate average fuel consumption (CAFC) and new energy vehicle (NEV) credits policy for passenger car enterprises (i.e., the CAFC \& NEV dual credits policy) in China's automobile industry. However, the current automobile test and evaluation standards are still not perfect, especially for the energy consumption standards for new energy vehicles, calling for the formulation of life cycle-based evaluation methods as soon as possible. On the other hand, China still faces a shortage of test standards and policies for commercial vehicles. After all, commercial vehicles contribute more than half of the carbon emissions in the automobile industry. It is necessary to establish a system for evaluating the average fuel consumption of commercial vehicle enterprises as soon as possible.

Second, fiscal and tax incentive policies can reduce the incremental cost of promoting new energy vehicles. It can accelerate the market-based development of new energy vehicles [68]. At present, the existing incentive policies mainly include fiscal subsidies, purchase tax exemption, and right-of-way policies for new energy vehicles. To further promote the low-carbon development of the automobile industry in the future, it is necessary to establish a comprehensive fiscal and tax policy system for the automobile industry from the perspective of the whole life cycle, which should include the production, consumption, and usage stages.

Third, based on controlling the fuel economy of enterprises, the corporate average fuel consumption of the CAFC \& NEV dual credits policy has been issued to promote the development of new energy vehicles [69]. In recent years, the CAFC \& NEV dual credits policy has achieved notable results in promoting the development of new energy vehicles. However, the fuel economy of conventional cars is falling rather than rising due to the implementation of the CAFC \& NEV dual credits policy. It needs to be optimized and adjusted in the future. It is suggested that the NEV credit policy should be phased out in due course according to industrial development. At the same time, the CAFC credit parameters should be determined in a scientific manner to ensure the gradual decrease of the average fuel consumption of automobile enterprises.

Finally, neither fiscal and tax incentive policies nor the CAFC \& NEV dual credits policy is directly related to carbon emissions; they only indirectly affect the carbon emissions of the automobile industry. In the future, the automobile industry needs to establish a policy, regulation, and standard system with carbon emission control policy as the core, as shown in Figure 7. The automobile industry's carbon emission control should aim to achieve the low-carbon development of the automobile industry and promote the development of energy conservation, emission reduction, and efficiency enhancement in the automobile industry in China.

Policies directly related to carbon emission control include carbon tax and carbon trading policies [70]. The carbon tax policy takes the carbon dioxide emissions from automobiles as the evaluation standard. It controls the application of highcarbon fuels and high-carbon automobile products by levying corresponding taxes and fees on vehicle fuels and vehicle purchases. The carbon trading policy is an instrument that endows carbon dioxide with a commodity property to achieve energy conservation and carbon emission reduction based on market regulation. It can control the total amount of carbon emissions [71]. Compared with foreign carbon trading policies, the carbon market in China lacks control over emissions from vehicles in public use. Some localities could try carbon-sharing programs to incentivize people to stop using conventional vehicles or switch to alternative energy sources [72].

In general, compared with the carbon tax policy, the carbon trading policy has the advantages of a definite emission reduction effect, flexible response measures for enterprises, lower 


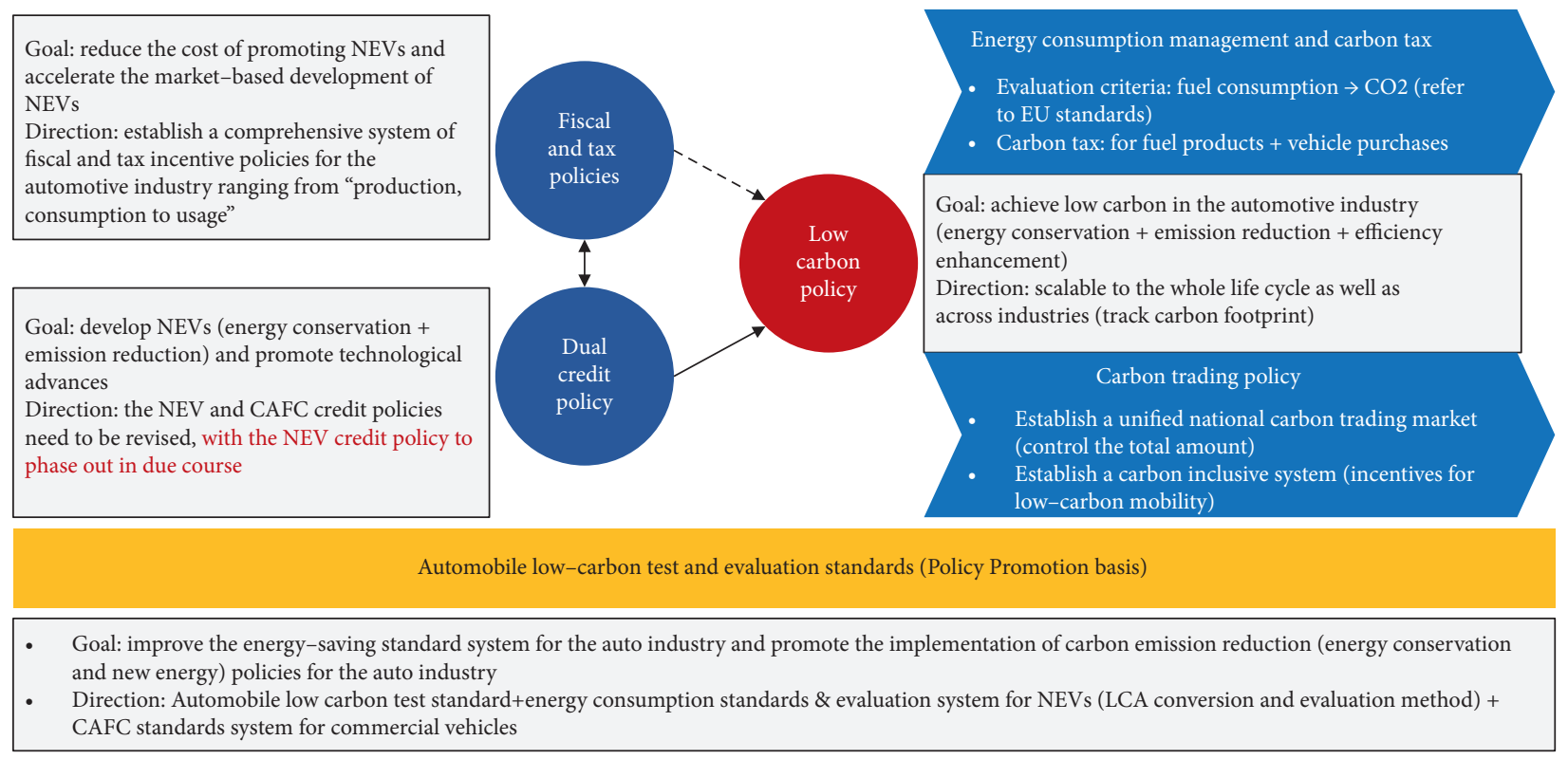

FIGURE 7: The low-carbon policy, regulation, and standard system with carbon trading policy as the core.

cost of emission reduction for the whole society, and low resistance to policy implementation. Therefore, the Chinese government should prioritize establishing a unified carbon trading market, incorporate the transport sector into the carbon trading market as soon as possible, and carry out relevant basic research on the transport sector's entry into the carbon trading market. Finally, it is suggested that China needs to improve the automobile test and evaluation standards, establish fiscal and tax incentive policies based on the whole life cycle consideration, and switch the dual credits policy to a carbon control policy. It is important to ensure the low-carbon transformation of the automobile industry. China should establish a low-carbon policy, regulation, and standard system with carbon trading as the core as soon as possible.

\section{Conclusion}

This paper systematically studies the challenges and opportunities brought about by the 30.60 Target and the coping strategies for the automobile industry. Through analysis, the following conclusions are drawn:

(1) Achieving the 30.60 Target is an environmental issue and a development issue. More importantly, it is a significant issue concerning human survival mode. It should be the fundamental starting point for all relevant emission reduction efforts of the country. In this sense, achieving carbon neutrality is a must. Achieving the 30.60 Target will mainly rely on carbon reduction technologies in the short term. At the same time, zero-carbon and negative carbon technologies will be necessary for the medium and long term. In the future, carbon emission reduction will become the most critical issue in China's social development, while the cost and other related issues will be of secondary importance.
(2) The automobile industry contributes a significant portion of carbon emissions to road transport and is an essential link in China's efforts to achieve the 30.60 Target. In particular, the automobile industry must effectively collaborate with other related industries and sectors to achieve carbon neutrality. The paths include joint carbon emission reduction by upstream and downstream players inside the industry and cross-industry and cross-sector coordinated decarbonization outside the industry. Meanwhile, the low-carbon policy and regulation system should be established to provide a direct driving force and fundamental guarantee for the low-carbon development of the automobile industry in China.

(3) Achieving the 30.60 Target is a systematic national project that is highly complex and interconnected. As the leader, adequate means, and carrier of national economic transformation and upgrading, the automobile industry should bear the brunt to achieve the carbon peaking and carbon neutrality goals. In the future, the automobile industry must make concerted efforts with other related industries from the whole life cycle perspective. Only in this way can the automobile industry effectively support China's historical transformation toward low-carbon and zero-carbon development.

\section{Conflicts of Interest}

The authors declare that there are no conflicts of interest.

\section{Authors' Contributions}

F.Z. and Z.L. designed the whole study; X.L. conducted data collection; X.L and H.Z. performed the modeling, analyzed 
the results, and wrote the paper; H.Z. and Z.L. revised and edited the paper. All authors have read and agreed to the published version of the paper.

\section{Acknowledgments}

This research was funded by the National Natural Science Foundation of China, with the funding account numbers of U1764265, 71774100, and 71690241.

\section{References}

[1] S. Fawzy, A. I. Osman, J. Doran, and D. W. Rooney, "Strategies for mitigation of climate change: a review," Environmental Chemistry Letters, vol. 18, no. 6, pp. 2069-2094, 2020.

[2] J. M. Chen, "Carbon neutrality: toward a sustainable future," Innovation, vol. 2, no. 3, 2021.

[3] Y. Li, K. Chen, N. Zheng, Q. Cai, Y. Li, and C. Lin, "Strategy research on accelerating green and low-carbon development under the guidance of carbon peak and carbon neutral targets," IOP Conference Series: Earth and Environmental Science, vol. 793, no. 1, 2021.

[4] M. Crippa, D. Guizzardi, and M. Muntean, "Fossil $\mathrm{CO}_{2}$ emissions of all world countries - 2020 Report," EUR 30358 EN, Publications Office of the European Union, Luxembourg, 2020.

[5] Z. Yuan, "Review on measures and paths for Low-carbon emission in China's transportation industry. Advances in Climate Change Research," 2021, https://d.wanfangdata.com. $\mathrm{cn} /$ periodical/qhbhyjjz202101004.

[6] P. R. C. Ministry of Ecology and Environment, "China Mobile Source Environmental Management Annual Report," 2020, https://www.mee.gov.cn/hjzl/sthjzk/ydyhjgl/.

[7] Y. Liu, Y. Liu, and J. Chen, "The impact of the Chinese automotive industry: scenarios based on the national environmental goals," Journal of Cleaner Production, vol. 96, pp. 102-109, 2015.

[8] J. Kejun, H. Chenmin, Z. Songli, X. Pianpian, and C. Sha, "Transport scenarios for China and the role of electric vehicles under global $2^{\circ} \mathrm{C} / 1.5^{\circ} \mathrm{C}$ targets," Energy Economics, vol. 103 , 2021.

[9] S. Hu, J. Yang, Z. Jiang, M. Ma, and W. Cai, " $\mathrm{CO}_{2}$ emission and energy consumption from automobile industry in China: decomposition and analyses of driving forces," Processes, vol. 9, no. 5, 2021.

[10] SAE-China, Technology Roadmap for Energy Saving and New Energy Vehicles 2.0, China Machine Press, Beijing, China, 2020.

[11] K. H. Lee, "Carbon accounting for supply chain management in the automobile industry," Journal of Cleaner Production, vol. 36, pp. 83-93, 2012.

[12] H. Hao, F. Liu, X. Sun, Z. Liu, and F. Zhao, "Quantifying the energy, environmental, economic, resource Co-benefits and risks of GHG emissions abatement: the case of passenger vehicles in China," Sustainability, vol. 11, no. 5, 2019.

[13] Q. Qiao, F. Zhao, Z. Liu, S. Jiang, and H. Hao, "Comparative study on life cycle $\mathrm{CO}_{2}$ emissions from the production of electric and conventional vehicles in China," Energy Procedia, vol. 105, pp. 3584-3595, 2017.

[14] Y. Wu, F. Liu, J. He, M. Wu, and Y. Ke, "Obstacle identification, analysis and solutions of hydrogen fuel cell vehicles for application in China under the carbon neutrality target," Energy Policy, vol. 159, 2021.
[15] W. Du, Q. Huang, and S. Grasso, "Analysis of global policy and impact on automobile industry under carbon neutrality," in Proceedings of the 2021 6th International Conference on Materials Science, Energy Technology and Environmental Engineering (MSETEE 2021), vol. 308, Hangzhou, China, August 2021.

[16] H. Du, Q. Li, X. Liu, B. Peng, and F. Southworth, "Costs and potentials of reducing $\mathrm{CO}_{2}$ emissions in China's transport sector: findings from an energy system analysis," Energy, vol. 234, 2021.

[17] G. M. Heggelund, "China's climate and energy policy: at a turning point?” Int Environ Agreem, vol. 21, pp. 1-15, 2021.

[18] M. Yao, H. Liu, and X. Feng, "The development of low-carbon vehicles in China," Energy Policy, vol. 39, no. 9, pp. 5457-5464, 2011.

[19] I. Azevedo, C. Bataille, J. Bistline, L. Clarke, and S. Davis, "Net-zero emissions energy systems: what we know and do not know," Energy and Climate Change, vol. 2, 2021.

[20] J. N. Kang, Y. M. Wei, L. C. Liu, and J. W. Wang, "Observing technology reserves of carbon capture and storage via patent data: paving the way for carbon neutral," Technological Forecasting and Social Change, vol. 171, 2021.

[21] C. Zou, B. Xiong, and H. Xue, "The role of new energy in carbon neutral," Petroleum Exploration and Development, vol. 48, no. 2, pp. 480-491, 2021.

[22] W. Tang, P. Wu, Y. Zhang, and X. Cao, "Analysis on the current situation and development trend of China's electrification level and electric energy substitution under the background of carbon neutral," IOP Conference Series: Earth and Environmental Science, vol. 661, no. 1, 2021.

[23] R. Chen, R. Zhang, and H. Han, "Climate neutral in agricultural production system: a regional case from China," Environmental Science and Pollution Research International, vol. 28, 2021.

[24] S. Chen, K. Fang, S. Dhakal, A. Kharrazi, K. Tong, and A. Ramaswami, "Reshaping urban infrastructure for a carbonneutral and sustainable future," Resources, Conservation and Recycling, vol. 174, 2021.

[25] W. Zhang, "A framework of the carbon-neutral auditing for enterprises in China," American Journal of Industrial and Business Management, vol. 3, no. 3, pp. 262-265, 2013.

[26] M. Akhshik, S. Panthapulakkal, J. Tjong, A. Bilton, C. V. Singh, and M. Sain, "Cross-country analysis of life cycle assessment-based greenhouse gas emissions for automotive parts: evaluation of coefficient of country," Renewable and Sustainable Energy Reviews, vol. 138, 2021.

[27] Z. Liu, P. Ciais, and Z Deng, "Near-real-time monitoring of global $\mathrm{CO}_{2}$ emissions reveals the effects of the COVID-19 pandemic," Nature Communications, vol. 11, no. 1, 2020.

[28] P. Friedlingstein, M. O’Sullivan, and M. W. Jones, "Global carbon budget 2020," Earth System Science Data, vol. 12, no. 4, pp. 3269-3340, 2020.

[29] J. He, Z. Li, and X. Zhang, "Comprehensive report on China's long-term low-carbon development strategies and pathways," Chinese Journal of Population, Resources and Environment, vol. 18, no. 4, pp. 263-295, 2020.

[30] K. Li, Y. Yan, and X. Zhang, "Carbon-abatement policies, investment preferences, and directed technological change: evidence from China," Technological Forecasting and Social Change, vol. 172, 2021.

[31] W. Tang, Y. Weng, Y. Zhang, and X. Cao, "Path analysis of implementing carbon neutral target in customer side of power grid company," IOP Conference Series: Earth and Environmental Science, vol. 661, no. 1, 2021. 
[32] J. Hong, G. Q. Shen, Y. Feng, W. S. T. Lau, and C. Mao, "Greenhouse gas emissions during the construction phase of a building: a case study in China," Journal of Cleaner Production, vol. 103, pp. 249-259, 2015.

[33] L. Ren, S. Zhou, T. Peng, and X. Ou, "A review of $\mathrm{CO}_{2}$ emissions reduction technologies and low-carbon development in the iron and steel industry focusing on China," Renewable and Sustainable Energy Reviews, vol. 143, 2021.

[34] W. Xie, W. Guo, W. Shao, F. Li, and Z. Tang, "Environmental and health Co-benefits of coal regulation under the carbon neutral target: a case study in anhui province, China," Sustainability, vol. 13, no. 11, 2021.

[35] C. Chilev and F. D. Lamari, "Hydrogen storage at low temperature and high pressure for application in automobile manufacturing," International Journal of Hydrogen Energy, vol. 41, no. 3, pp. 1744-1758, 2016.

[36] G. R. Yu, X. J. Zhu, and Y. L. Fu, "Spatial patterns and climate drivers of carbon fluxes in terrestrial ecosystems of China," Global Change Biology, vol. 19, no. 3, pp. 798-810, 2013.

[37] Y. Weng, W. Cai, and C. Wang, "Evaluating the use of BECCS and afforestation under China's carbon-neutral target for 2060," Applied Energy, vol. 299, 2021.

[38] Energy Foundation, Comprehensive Report on China's Carbon Neutrality. 2020 China's New Journey of Modernization: The New Growth Story from the 14th Five-Year to Carbon Neutrality, Energy Foundation, Beijing, China, 2020.

[39] H. Hao, H. Wang, and R. Yi, "Hybrid modeling of China's vehicle ownership and projection through 2050," Energy, vol. 36, no. 2, pp. 1351-1361, 2011.

[40] China Association of Automobile Manufacturers, "New Energy Vehicle Production and Sales Continue to Break New Records in July 2021," 2021, https://www.caam.org.cn/chn/4/ cate_154/con_5234371.html.

[41] M. Frondel, C. M. Schmidt, and C. Vance, "A regression on climate policy: the European Commission's legislation to reduce $\mathrm{CO}_{2}$ emissions from automobiles," Transportation Research Part A: Policy and Practice, vol. 45, no. 10, pp. 1043-1051, 2011.

[42] Q. Qiao, F. Zhao, Z. Liu, X. He, and H. Hao, "Life cycle greenhouse gas emissions of Electric Vehicles in China: combining the vehicle cycle and fuel cycle," Energy, vol. 177, pp. 222-233, 2019.

[43] L. Liu, C. Chen, Y. Zhao, and E. Zhao, "China's carbonemissions trading: overview, challenges and future," Renewable and Sustainable Energy Reviews, vol. 49, pp. 254-266, 2015.

[44] W. Chang, B. Liu, and Y. Zhu, "The development trend of the automobile industry under the dual-carbon goal," Automobile Aspects, vol. 8, pp. 31-35, 2021.

[45] H. Hao, Y. Geng, and J. E. Tate, "Impact of transport electrification on critical metal sustainability with a focus on the heavy-duty segment," Nature Communications, vol. 10, no. 1, 2019.

[46] F. Zhao, K. Chen, H. Hao, and Z. Liu, "Challenges, potential and opportunities for internal combustion engines in China," Sustainability, vol. 12, no. 12, 2020.

[47] Y. Chen, J. Ma, B. Han et al., "Emissions of automobiles fueled with alternative fuels based on engine technology: a review," Journal of Traffic and Transportation Engineering, vol. 5, no. 4, pp. 318-334, 2018.

[48] C. W. Su, X. Yuan, R. Tao, and M. Umar, "Can new energy vehicles help to achieve carbon neutrality targets?" Journal of Environmental Management, vol. 297, Article ID 113348, 2021.
[49] R. Cervero and K. Kockelman, "Travel demand and the 3Ds: density, diversity, and design," Transportation Research Part D: Transport and Environment, vol. 2, no. 3, pp. 199-219, 1997.

[50] L. Yang, K. W. Chau, W. Y. Szeto, X. Cui, and X. Wang, "Accessibility to transit, by transit, and property prices: Spatially varying relationships," Transportation Research Part D: Transport and Environment, vol. 85, 2020.

[51] L. Yang, X. Chu, Z. Gou, H. Yang, Y. Lu, and W. Huang, "Accessibility and proximity effects of bus rapid transit on housing prices: heterogeneity across price quantiles and space," Journal of Transport Geography, vol. 88, 2020.

[52] F. Liu, F. Zhao, Z. Liu, and H. Hao, "Can autonomous vehicle reduce greenhouse gas emissions? A country-level evaluation," Energy Policy, vol. 132, pp. 462-473, 2019.

[53] M. Ghosh, A. Ghosh, and A. Roy, "Renewable and sustainable materials in automotive industry," in Encyclopedia of Renewable and Sustainable Materials 2020, pp. 162-179, Elsevier, Amsterdam, Netherlands, 2019.

[54] Y. Li, K. Fujikawa, J. Wang, X. Li, Y. Ju, and C. Chen, "The potential and trend of end-of-life passenger vehicles recycling in China," Sustainability, vol. 12, no. 4, 2020.

[55] H. Hao, Q. Qiao, Z. Liu, and F. Zhao, "Impact of recycling on energy consumption and greenhouse gas emissions from electric vehicle production: the China 2025 case," Resources, Conservation and Recycling, vol. 122, pp. 114-125, 2017.

[56] L. Zhang, R. Jiang, Z. F. Jin, H. H. Huang, X. Y. Li, and Y. J. Zhong, "CAD-based identification of product low-carbon design optimization potential: a case study of low-carbon design for automotive in China," International Journal of Advanced Manufacturing Technology, vol. 100, no. 1-4, pp. 751-769, 2018.

[57] J. Köhler, W. Schade, G. Leduc, T. Wiesenthal, B. Schade, and L. Tercero Espinoza, "Leaving fossil fuels behind? An innovation system analysis of low carbon cars," Journal of Cleaner Production, vol. 48, pp. 176-186, 2013.

[58] K. Chen, F. Zhao, X. Liu, H. Hao, and Z. Liu, "Impacts of the new worldwide light-duty test procedure on technology effectiveness and China's passenger vehicle fuel consumption regulations," International Journal of Environmental Research and Public Health, vol. 18, no. 6, 2021.

[59] Z. Wu, Q. Shao, Y. Su, and D. Zhang, "A socio-technical transition path for new energy vehicles in China: a multi-level perspective," Technological Forecasting and Social Change, vol. 172, 2021.

[60] Y. Zheng, X. He, and H. Wang, "Well-to-wheels greenhouse gas and air pollutant emissions from battery electric vehicles in China," Mitigation and Adaptation Strategies for Global Change, vol. 25, no. 3, pp. 355-370, 2019.

[61] B. Borlaug, M. Muratori, and M. Gilleran, "Heavy-duty truck electrification and the impacts of depot charging on electricity distribution systems," Nature Energy, vol. 6, no. 6, pp. 673-682, 2021.

[62] Y. Zhang, Y. Liu, H. Lv, S. Chen, and S. Li, "Dynamic analysis of platinum material flows and stocks with hybrid MFA method aiming to carbon neutral targets of automotive industry in China," Environmental Pollutants and Bioavailability, vol. 33, no. 1, pp. 194-205, 2021.

[63] Z. Liu, X. Liu, H. Hao, F. Zhao, A. A. Amer, and H. Babiker, "Research on the Critical Issues for Power Battery Reusing of New Energy Vehicles in China," Energies, vol. 13, no. 8, 2020.

[64] B. Niu, X. Yu, and Z. Shen, "Structure Adjustment of Automobile Supply Chain Facing Low-carbon Emission Standard," Resources, Conservation and Recycling, vol. 171, 2021. 
[65] M. Isik, R. Dodder, and P. O. Kaplan, "Transportation emissions scenarios for New York City under different carbon intensities of electricity and electric vehicle adoption rates," Nature Energy, vol. 6, no. 1, pp. 92-104, 2021.

[66] M. Longo, W. Yaici, and F. Foiadelli, "Future developments in vehicle-to-grid technologies," in Solving Urban Infrastructure Problems Using Smart City Technologies, pp. 613-629, Elsevier, Amsterdam, Netherlands, 2021.

[67] J. Li, "Charging Chinese future: the roadmap of China's policy for new energy automotive industry," International Journal of Hydrogen Energy, vol. 45, no. 20, Article ID 11409, 2020.

[68] X. Zhu, M. Ren, G. Wu, J. Pei, and P. M. Pardalos, "Promoting new energy vehicles consumption: the effect of implementing carbon regulation on automobile industry in China," Computers \& Industrial Engineering, vol. 135, pp. 211-226, 2019.

[69] Y. Wang, F. Zhao, Y. Yuan, H. Hao, and Z. Liu, "Analysis of typical automakers' strategies for meeting the dual-credit regulations regarding CAFC and NEVs," Automotive Innovation, vol. 1, no. 1, pp. 15-23, 2018.

[70] Z. Y. Zhao, L. Gao, and J. Zuo, "How national policies facilitate low carbon city development: a China study," Journal of Cleaner Production, vol. 234, pp. 743-754, 2019.

[71] Y. J. Zhang and W. Wang, "How does China's carbon emissions trading (CET) policy affect the investment of CETcovered enterprises?" Energy Economics, vol. 98, 2021.

[72] W. Li, R. Long, H. Chen, T. Yang, J. Geng, and M. Yang, "Effects of personal carbon trading on the decision to adopt battery electric vehicles: analysis based on a choice experiment in Jiangsu, China," Applied Energy, vol. 209, pp. 478-488, 2018. 